\title{
Exploration of external indicators of social change in postmodern communities
}

\author{
Marta Botta
}

Received: 29 September 2014 / Accepted: 11 December 2014 / Published online: 29 January 2015

(C) The Author(s) 2015. This article is published with open access at Springerlink.com

\begin{abstract}
The current study explores external indicators of social change through the lens of Sorokin's theory of cultural dynamics; utilising case studies of two master built communities from vastly different cultural and geographic backgrounds (Sippy Downs, Australia, and Masdar City, United Arab Emirates). These two communities are contrasted to gain insight into the dynamics of social change in the 21 st century. The study confirmed Sorokin's assumption that our Western society is in the late sensate phase of sociocultural development. Additionally, this late sensate phase was found to have common characteristics with the postmodern paradigm. Further, results of the residents' survey confirmed Sippy Downs as an integrated logico-meaningful culture in a postmodern environment. This finding justified the inclusion of this particular population in the current study as a model of a typical postmodern community. Additionally, weak signals indicating the emergence of the next idealistic phase of sociocultural change were detected in both communities, although there was a variance in the nature of these signals. The study also revealed that sustainability thinking appeared to be the bridge to the next idealistic phase of sociocultural development. However, Causal Layered Analysis revealed a lopsided approach to sustainability: an overemphasis of green technology
\end{abstract}

Electronic supplementary material The online version of this article (doi:10.1007/s40309-014-0061-6) contains supplementary material, which is available to authorized users.

\section{Botta}

Sustainability Research Centre, Faculty of Arts and Business, University of the Sunshine Coast, Locked Bag 4, Maroochydore DC, Queensland 4558, Australia

\section{Botta ( $\bowtie)$}

14, Oxford Close, Chancellor Park, QLD4556, Australia

e-mail: Marta.Botta@research.usc.edu.au

M. Botta

e-mail: mbharmony@gmail.com over the need for social innovation. The socio-semiotics analysis of urban design and architecture in the context of the two case studies elicited a plausible pattern of sociocultural change. The combination of qualitative and quantitative methods using the Explorative Mixed Methods Research Design enhanced the analysis and increased the robustness of the results.

Keywords Social change $\cdot$ Macrohistory $\cdot$ Postmodern architecture $\cdot$ Socio-semiotics $\cdot$ Mixed methods · Neopragmatic postmodernism

\section{Introduction}

The rapidly changing social environment of the 21 st century is providing a rich and complex fabric of socio-cultural layers to explore. The current study is exploring social change through external indicators comprising tangible physical structures and artefacts such us urban design, infrastructure and architecture. However, social phenomena have both exterior and interior dimensions [1-4]. Therefore, focusing on external manifestations must include analysis of their internal causation, since as Sorokin [5] postulates, there is a strong link between inner thought processes, worldviews and external phenomena, due to a propensity to "incorporate, or realize, or externalise, the internal experience" [5, p. 20]. More specifically, Daffara [6] suggests that cultures express their spirit, episteme and cosmology through architecture. Thus, to facilitate understanding of the dynamics and causation of cultural change it is essential to place the external representations of the given society into a social context. 
Postmodernism as a social and cultural phenomenon has been gradually taking foothold in most areas of western society from the middle of the twentieth century. The postmodern movement is typically opposing the previous modern era [7], which according to Sardar [8] was characterised by unidirectional progress, destroying cultures and communities and causing environmental degradation. Therefore, it is timely that the sustainability agenda is gaining prominence in postmodern society. The destructive unsustainable path is countered by the aspiration of the postmodern philosophical movement proposing deconstruction and reordering of knowledge along a different paradigm. This process would consequently lead to "insurrection of subjugated knowledges" [9, p. 7], to aid transformation toward a more inclusive society.

Nonetheless, alerting to the layered nature of social reality Inayatullah [10, p. 489] warns that "There is no simple global solution without worldview transformation". Further, Sardar [11] expands the discourse with a new multicultural dimension by urging decolonisation of the future from the modernist Western classifications of knowledge. Thus, the purpose for the inclusion of one of the case studies in the current paper was to demonstrate a non-Western multicultural approach to place making in a context of a sustainable postmodern community of the future. Accordingly, this study will contrast values and worldviews of a typical Western postmodern sustainable community with those of a Middle Eastern eco-city development possessing an inherently composite worldview by merging Eastern and Western thinking.

Masdar City in the United Arab Emirates is a hypermodern purpose designed technologically advanced prototype of a sustainable community where all current residents are exploring sustainable living options. On the other hand, the second case study - Sippy Downs, Australia is an established conventional community where not all the current residents are dedicated to sustainable living practices. Many have chosen the location for its proximity to schools, property prices and other practical/material considerations; although the original 'mission statement' of the development was specifically geared toward sustainability. However, in spite of some tension between the 'old' and the'new', and inconsistencies in pursuing sustainability objectives, the community is demonstrating potential for transformation in the context of the postmodern mainstream Australian society.

\section{The theoretical framework}

Overview of the spatial theory used

Architecture acquired an enhanced significance in postmodern society and is no longer merely a subject of aesthetics; it is considered a spatial representation of underpinning worldviews, to be analysed through the lens of social sciences. Spatial theories are currently gaining prominence not only in the social sciences, but also in architecture [12-14], since they can facilitate insight into the ongoing social changes evident through analysis of the urban environment.

Postmodernism in architecture is often viewed as a "negation of modernism, but without a specific style or ideology" [15, p. 127]. Modernist architecture with its large scale, overt functionality, simplicity and vertical lines had to give way to emerging architectural ideologies such as anthropometism (buildings at a smaller scale). The emerging postmodern architecture in the mid 20th century would display eclectic forms. These forms often include classical elements such as columns and curves. According to Anthony [16] curves induce a higher order of harmony and connectivity through entrainment, while the observer visually traces a curved pattern. Consequently, reintroduction of curves in postmodern architecture is bound to have a harmonising effect.

As opposed to the functionality of modernist architecture postmodernism regards space as independent and autonomous to be shaped according to aesthetic aims without a social objective [7]. The main determining features of postmodern architecture are identified by Jencks [2] as the as juxtaposition of tastes, pluralism, urbane urbanism, anthropomorphism, anamnesis, return to painting, the unexpected, multivalence, strange forms, new rhetorical figures, and return to absent centre - when the culture has a sense of departure but no clear sense of direction.

Social change explored through the lens of neopragmatic postmodernism

The analysis of temporal and spatial dimensions of postmodern architecture is framed within Sorokin's theory of social change, encompassing the macrohistorical perspective [10, 17]. This study postulates that Sorokin's pendulum theory [17] as a methodological framework can accommodate and explicate the sociocultural characteristics of postmodern society; and by embedding these characteristics into a wider historic context of super-rhythms it can offer further insight into probable future outcomes. These super-rhythms consist of two distinct phases: ideational phase - characterised by reality as nonmaterial, and spiritual, striving for "self-imposed minimization or elimination of most of their physical needs" and the opposite of the ideational phase, the sensate phasepreoccupied with modification or exploitation of the external world and "it assumes an agnostic attitude towards the entire world beyond the senses"[5] p. 27]. The pendulum is a analogy for a movement between the sensate (materialistic) phase and ideational (spiritual) phase of sociocultural development (Fig. 1). Moreover, in the transitional period between those two extremes, the culture attempts to integrate both sides 
Fig. 1 Preference for design features in future local developments in Sippy Downs, Australia

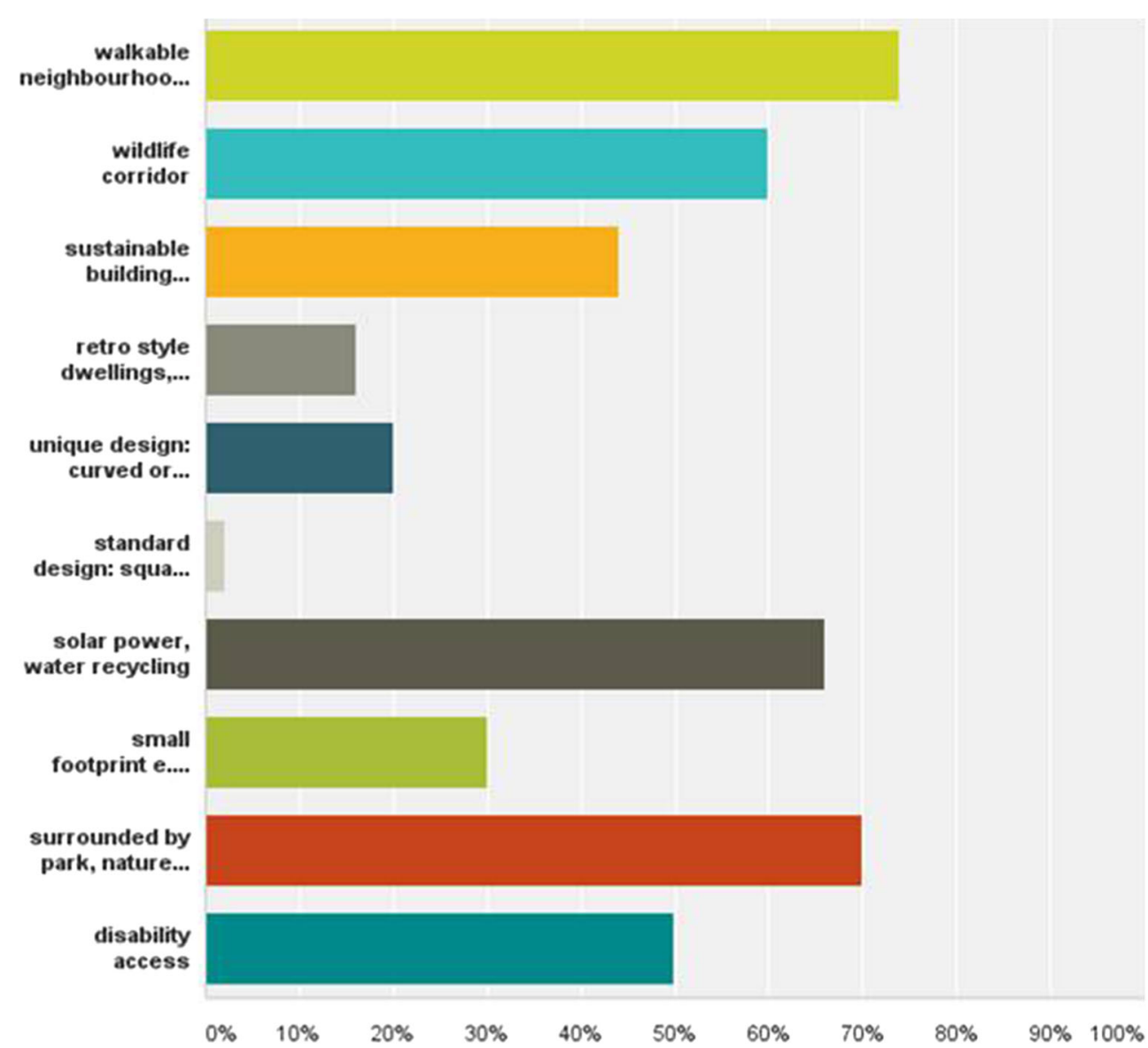

during the idealistic (rational) phase, which only accepts the truth "when it appears to be reasonable and reconcilable with the logical laws of the human mind..." [5] p. 227].

Most macrohistorians including Sorokin offer a singular evolutionary path, that appears to be in epistemological tension with pluralism inherent to the postmodern worldview, and seems to be in conflict with the preference of futures work for open ended multiple outcomes. The current study is attempting to merge these apparent polarities by employing a novel lens of neopragmatic postmodernism [18]. According to Minda [19] neopragmatic postmodernism denotes postmodern critique, which goes beyond the truth claims of modernity, however, for empirical investigation it utilises theory as a tool. In the current study Sorokin's theory of cultural and social dynamics is utilised as a tool of investigation in the context of neopragmatic postmodernism. Pragmatism as a theoretical framework in futures work is endorsed by Bussey [20]; suggesting that futures work is essentially pragmatic, since it considers our thinking as well as our actions as zones of multiplicity. Further, Minda [19] distinguishes the neopragmatic approach from standard poststructural criticism, and he goes beyond mere criticism by advocating a practical approach to problem solving. In that respect, the neopragmatic approach employed in this study can potentially constitute a new stream within futures; going beyond poststructuralism and postmodernism to post-postmodernism (?).

\section{Methods}

\section{Mixed methods}

Exploration of internal and external indicators of social change in postmodern communities in this study is performed through the Mixed Methods Research Design (MMRD). This multiple methods design was chosen due to its association with postmodernism, favouring multiple perspectives [21]. According to Nigel [21], MMRD as an applied multiple method, can make the research epistemologically sound by providing analytic density. This analytic density is built up by addressing all the relevant factors through historical, structural and cultural dimensions [21], thus MMRD is particularly suitable for the current socio-cultural analysis. The advantage of using quantitative research methods in conjunction with qualitative research lies in conveying sophistication to understanding and explanation of social phenomena [22]. Mixed methods gained acceptance amongst researchers in the 1980s, since they addressed epistemological ontological and 
axiological weaknesses of both the qualitative and quantitative approaches [22].

According to Creswell, and Plano Clark [23] there are four major mixed methods designs; triangulation, embedded design, explanatory design and exploratory design. Other authors are suggesting a proliferation of various types of mixed designs, however, the Exploratory Design was chosen for this analysis due to its specific structure. In the Exploratory Design priority is given to qualitative research methods [23]. The first phase of the two-phase structure utilises qualitative methods such as CLA to analyse the two case studies. Additionally, socio-semiotic analysis will elucidate the connection between external and internal dimensions of postmodern architecture, and will give indication of development beyond postmodernism. An advantage of using the Exploratory Design for the current study is that it enables the development of an instrument (a survey) as one was not readily available. Karlsen, Øverland, \& Karlsen [24] also postulate that mixed design is appropriate for futures studies as it promotes 'good research' by combining the best of both methods (qualitative and quantitative).

Merging qualitative and quantitative research methods: causal layered analysis, survey, and socio-semiotic analysis

Causal Layered Analysis (CLA) is one of the primary qualitative research tools in this study. CLA offers analysis on four vertical levels: litany, social causes, discourse/ worldview and myth/metaphor [25]. Accordingly, Bussey [26] proposes to utilise CLA as a vehicle to analyse the dynamic layered and multiple nature of social reality. Thus, the use of CLA in the current study is well suited for in-depth analysis of complex underlying issues involved in social change processes. Additionally, Inayatullah [10, p. 815] postulates that CLA"is inclusive of different ways of knowing". Thus, CLA is particularly suitable for the current analysis, since one of the case studies (Masdar) presents novel non-Western worldviews.

The CLA works well with the specifically designed residents' survey. This survey instrument was assembled by incorporating inputs from the CLA, and to ascertain the current position of the sustainable community on the continuum of the super-rhythm of sociocultural development [27].

Since futures research is an interdisciplinary methodology [28], in addition to the above methods, this research also adopts socio-semiotic analysis, to specify it to the spatial dimensions central to the current study. Generally, semiotics as a linguistic tool focuses on the processes of meaning making. However, socio-semiotics, as a more contemporary form of postmodern urban semiotics, is a combination of sociology and spatial semiotics, which is derived from architectural semiotics [15]. As an expansion of classical semiotics, sociosemiotics also analyses exo semiotic dimensions such as production of space, politics and economy. In fact, the reciprocal relationship between ideology and material objects (such as buildings) is the principal aim of a socio-semiotic analysis.

Case studies and analysis

\section{Masdar City}

Masdar City is the first eco-city in the world and is hailed as a model of urban environmental sustainability (Lau 2012). The city is the culmination of several decades of theoretical research into sustainable development (Joss, 2010). The construction of Masdar City started in 2007 on a desert area near the Abu Dhabi airport. The city is planned as a highly sustainable community, using only renewable energy and utilising innovative building technology combined with some traditional design features. Once finished Masdar City is going to be of sizeable proportions. It will house 40,000 residents, 50,000 commuters, and more than 1,500 businesses and educational institutions including a university at it's centre, dedicated to cutting edge research with a sustainability focus. The design and technology of Masdar City is reflecting the aspirations of a large international team of environmentally conscious concept developers.

Considering Masdar City in the context of the United Arab Emirates it is obvious that it has a unique role to play. It is part of a new progressive sustainable image, promoted by HH Sheikh Mohammed bin Zayed Al Nahyan, crown prince of Abu Dhabi. Masdar City aspires to be "a global hub of energy and sustainability" $[29$, p. 2]. Masdar is setting an example by banning petrol driven cars on its streets and provides an attractive free of charge alternative in the form of a network of small electric cars called personal rapid transport (Online Resource 1).

\section{Sippy downs}

The second case study is focusing on an Australian community, with similar ambitions, to achieve a high level of sustainability. Sippy Downs is situated at the centre of Sunshine Coast. It was established in 1993 and is built around the University of the Sunshine Coast, with the attached Innovation Centre, housing the prominent Sustainability Research Centre. In fact, Sippy Downs has been master planned as Australia's first university town and was designated as a 'Knowledge Hub' in the Queensland Government's South East Queensland Infrastructure Plan [30]. Other schools in Sippy Downs include the Siena Catholic College, Chancellor State College and a Montessori College. These schools attracted a large number of new residents in the past 6 years, and by 2011 there had been a 10 -fold increase in population amounting to 9,727 residents according to the latest census [30].

The local council voiced aspirations to become Australia's most sustainable region (Sunshine Coast Council 2011), and to support this endeavour it adopted the Sunshine Coast Climate Change and Peak Oil 
Strategy to increase resilience and guide the transition to reduced carbon and oil consumption. Sippy Downs, housing the University of the Sunshine Coast (USC) is designed to be a showcase of sustainability.

\section{CLA: contrasting Masdar City and Sippy downs}

According to Inayatullah futures research is involved in the exploration of "possible, probable and preferable futures and of the worldview and myths that underlie each future" $[25, \mathrm{p}$. 1]. CLA as a futures analytic tool is designed to reveal the layered nature of reality through vertical dimensions such as worldviews and myth of a given situation, thus it has the scope to carry the analysis of sustainable communities deeper into sociological, cultural and mythical spaces as outlined in Table 1.

On the litany level both communities have common themes; they are founded on principles fostering sustainability and education. Another common feature is that they were both supported by local authorities right from the outset. Sippy Downs' sustainable development is promoted by the local council and the local Innovation Centre is holding regular events sponsored by regional authorities. Similarly, Masdar Institute hosts many international sustainability related functions, some of them sponsored by Sheikh Mohammed bin Zayed himself [29]. On the system level these two communities differ substantially from the original grass roots sustainable communities worldwide, living in subsistence mode on the fringes of society. Therefore the two case studies may represent the next transitional stage in sociocultural development, by mirroring growing societal acceptance of progressive ideas.

On the worldview level, attitudes towards sustainability are more relaxed in Sippy Downs, since there are no urgently pressing issues to threaten the status quo. This half hearted attitude is consistent with the passive sensate cultural mentality [5]. On the other hand, UAE feels the need to be more proactive about sustainability, thus is a step ahead of Sippy Downs. The country's rulers are acutely aware that oil will run out 1 day, and since
UAE is built on oil, alternative sources of income need to be sought to eliminate a potential collapse. UAE sees the solution in fostering both tourism and sustainable sources of energy with the aim of becoming the silicon valley for green energy [31].

According to Joss [31] most eco-cities focus on technological innovation, ignoring social and cultural aspects such as social justice and local democracy. In the case of Masdar culturally bound social dissonance is not obvious at present, perhaps due the general affluence of the population. The metaphor for Masdar City - being in an arranged marriage, is pointing to potential pitfalls of arranging the external elements of life meticulously while the inherent dichotomy of the situation is ignored. Masdar is essentially an Arabic autocratic collectivist community. However, at the same time it is courting the individualistic democratic West, and exposing the local population to outside cultural influences. This cultural hybridity [32] may either bring balance if handled skilfully or result in clashes of worldviews, as demonstrated in surrounding areas through the upheavals of the Arab Spring [33].

In Sippy Downs the USC has been widely advertising the image of being the best of both worlds (nature and culture) to attract both local and overseas students. Supported by the local government, favoured by sea changers as one of the prettiest places in Australia, the pitfall of this myth can be complacency of a spoilt child (as a metaphor) and a resulting flagging motivation to continue on the path of improvement. However, unless there is consistent push toward sustainability, the results may become just half baked.

\section{Socio-semiotic analysis of Masdar City and Sippy downs}

Masdar is considered to be a sustainable city of the future, and an example to follow $[34,35]$. Although at present it is only in its embryonic form it is already attracting plenty of interest worldwide. In comparison, Sippy Downs is relatively unknown internationally, however, its advantage in replicability

Table 1 CLA of two sustainable postmodern communities

\begin{tabular}{|c|c|c|}
\hline Layers & Sippy downs & Masdar city \\
\hline Litany & $\begin{array}{l}\text { Education is important for our future starting } \\
\text { small - develop later sustainable image makes us } \\
\text { look progressive }\end{array}$ & $\begin{array}{l}\text { Sustainable ways is the future for our country, and we can afford it } \\
\text { only the best will do no matter how long it takes to finish the } \\
\text { project }\end{array}$ \\
\hline System & $\begin{array}{l}\text { Local building industry real estate companies } \\
\text { knowledge industry - schools USC \& Innovation } \\
\text { Centre Sunshine Coast Regional Council }\end{array}$ & $\begin{array}{l}\text { Global sustainability firms Masdar Institute of Technology Sheikh } \\
\text { Mohammed bin Zayed }\end{array}$ \\
\hline Worldview & $\begin{array}{l}\text { We are different, more sustainable options are fine } \\
\text { as long as we don't have to give up our creature } \\
\text { comforts }\end{array}$ & $\begin{array}{l}\text { Oil reserves are limited, we have to be prepared for life after petrol, } \\
\text { we have to show to the world how to do sustainability, we are } \\
\text { leaders, tourists come to admire our work }\end{array}$ \\
\hline Myth/Metaphor & $\begin{array}{l}\text { Mother's favourite child - there is acknowledgement } \\
\text { and support by the local government we have the } \\
\text { best of both worlds }\end{array}$ & $\begin{array}{l}\text { Arranged marriage - planned merging of unknown components with } \\
\text { potential for future friction }\end{array}$ \\
\hline
\end{tabular}


since it is a smaller scale master built community. Although visually and culturally the two communities are quite different, they both share a common goal of sustainability.

Architectural paradigm Each of the analysed communities contains a university at the epicentre of the development. These universities, University of the Sunshine Coast (USC) and Masdar Institute are analysed as signs along the associational axis. The obvious purpose of the university buildings is education. However, the university also signifies a sense of identity for the surrounding community: as a university town in Sippy Downs, and as a sustainability knowledge center in Masdar.

The objective of the 21 st century, to become a knowledge society where knowledge is commoditised and becomes part of the market economy is in accordance with the postmodern paradigm and the materialistic sensate society. Since the 1980s there was a gradual shift in the focus of Western universities from the production of academic knowledge to the fostering of employable candidates ready to compete in the 'dog eats dog' environment of late capitalism [36].

According to Inayatullah [37, p. 19] "we need social technologies to repair the damage we have caused to ourselves, to nature and to others". The solution seem to lie in social engineering inspired by peace studies [38] education about gender equity [39] and sustainability [40]. USC is one of the handful of universities worldwide incorporating these concerns through their futures studies education, however, Masdar Institute although innovative in nature, is still entirely technology oriented. The 'deification' of science through current academic establishments such as the Masdar Institute confirms the position of the culture as a product of the late sensate period of societal development.

Economic considerations are also prominent in both universities. Recently, development came to a halt in Masdar City due to the GFC, resulting in restraint being exercised by developers and investors. In Australia, the government is urging universities to act as businesses and compete in the marketplace. Government subsidies are diminishing and the USC has to survive by boosting the numbers of fee paying overseas students to increase revenue. These developments are further confirmation of the accuracy of predictions of early last century scholars $[5,41]$ about the perils of the rampant neoliberalism of the late sensate sociocultural phase.

The motif of the USC complex is a fibro beach shack, regarded by John Mainwaring, co-designer of the multi-award winning USC Library (Online Resource 2) a typical Australian coastal architecture, with simplicity and unpretentiousness [42]. Thus most buildings at the USC display vernacular styles reminiscent of local historic patterns. Vernacular architectural style along with historic/nostalgic features is typical in postmodern architecture $[2,7]$. Apart from the university, a large number of residential dwellings in the Sippy Downs area also derives inspiration from history as demonstrated in "Online Resource 3"; indicating anamnesis, nostalgia, and pastiche - hallmarks of postmodern architecture, as described by Jencks [2].

Throughout the USC innovative practices were implemented for natural air-conditioning (chilled water to supply cool buildings), high loft ceilings designed for natural air circulation and prominent thermal chimneys on most buildings (Online Resource 4) . Many of these structures have odd shapes and unexpected angles including the ' $\mathrm{J}$ ' building and the art gallery tilting dangerously to one side (Online Resource 5). These strange forms and dissonant beauty as a displacement of convention as well as stylistic pluralism are typical of postmodern architecture [2]. Diversity in architectural styles at the USC has a connotative secondary function, mirroring complexity and pluralism inherent to the late capitalist society, as well as reflecting the notion that the culture has no unified sense of direction.

Both case studies display a large number of connotative codes pertaining to a sustainability typology. Masdar City is a pompous display of a futuristic vision (see details in "Online Resource 6"). As a display home of sustainability it boosts a massive $10 \mathrm{MW}$ solar photovoltaic plant built across 22 hectares, powering the institute. The motif of the whole complex displays more homogeneity than Sippy Downs. Despite of a clear futuristic leaning displayed in some buildings like the Knowledge Centre covered by a spherical roof with solar panels (Online Resource 7) and the stainless steel Wind Tower for cooling, modelled on traditional building practices (Online Resource 8), it resembles a socio-spatial experience of the past with small squares, exclusive pedestrian traffic and narrow streets. It is evident that inspiration was borrowed from traditional Arabic architecture, particularly in the design of the Masdar Institute itself, with window screens bearing a resemblance to the classical intricate mashrabiya latticework (Online Resource 9). These particular designs are clusters of a classic Arabic singular stellation (Sutton, 2007), however, the wavy façade is lending it a more contemporary postmodern feel.

The window shields, nonetheless, are not just decorations. Apart from shielding the interior from the sun the curves provide an angled view to protect the privacy of the inhabitants. Privacy is important in Arabic culture and accordingly the campus is segregated by gender, separating the living quarters for single men and women and families. However, the function and connotations of the traditional Islamic ornament go even deeper. According to Sutton [43, p. 50] "It seeks to compensate for the spiritual losses of civilisation by reestablishing something of the primordial beauty of virgin nature, and to transport the viewer from immersion in the mundane to serene contemplation". The expressed sentiment (spirituality) can be seen as an indication of Masdar's movement toward the ideational phase of societal development. 
This dimension is in contrast with the multifarious utilitarian design of the USC in Sippy Downs, catering to a more secular community.

The syntagmatic dimension The analysis of this dimension requires a bird's eye view of the way space is engineered. Looking at the map of Sippy Downs at "Online Resource 10" it is obvious that there are no straight streets or regular rectangular blocks. Most streets are curved, although there is no need to negotiate any topographic obstacles, since most of the area is flat, built on reclaimed sugar cane fields. There are plenty of short cul-de-sacs lending interest. As a clear departure from classical town planning, there is no centralised city centre. The major shopping area is at the edge of the development close to the motorway, and so is the university, which is otherwise central to the purpose of the area (being a university town). The university itself follows the same spatial ordering as the town, with a complex network of paths spread over a large area. The pattern of buildings is not intuitive and gives a haphazard appearance both in size and style. This decentralised multivalence is in agreement with common postmodern building practices [2].

Unlike other universities, the USC encourages the general public to utilise the premises; and to achieve this goal a number of festivals and family friendly social and sports activities are taking place at the university grounds throughout the year. There is no fencing or clear demarcation of boundaries between the surrounding community and university either. To connect with the community the USC houses a large public bus terminal and a number of local bus routes run right through it. There is also a well attended art gallery, cafes and a bookshop catering for everyone. This syntagmatic arrangement is evidence of a pluralistic view and carries a typological meaning connoting the ideology of inhabitation [44] as a public space to bring people together for social purposes in a non-discriminatory manner. This pluralism, open minded attitudes and expressed multiculturalism (see survey results below) are features of a typical postmodern society.

On the other hand, current aspirations of Masdar Institute differ markedly from those of the USC. The Institute (and the surrounding Masdar City) is quite exclusive and permits need to be obtained before visiting in a group. It is only open to the general public from Sundays to Thursdays $8.30 \mathrm{am}-4.30 \mathrm{pm}$. Essentially, the institute is built as a city within a city (in the Masdar City context), resembling the structure of a Byzantine imperial palace. The Masdar Institute has substantial surrounding walls to shield it from the outside world, indicating a need for protection and introversion. This design feature is analogous with the worlds oldest university, the Al-Azhar mosque in Cairo, funded around $970 \mathrm{AD}$. The university is intended to be a peaceful centre for learning, yet, it resembles a fortress [45]. The reasons for this walled design for Masdar may be a need for protection from the elements or from potential intruders (?).

The urban design of the future Masdar City reveals an organised cityscape designed as a mesh with parallel streets crossing in right angles. The institute, hotel and conference centre and Masdar headquarters form the central city area. The rapid rail line crosses the city through the middle, with an obvious aim of making public transport accessible from most locations. The topographic perspective the city's layout reveals a centralised urban design representing balance and order. This is in stark contrast to Sippy Downs with its irregular shapes and seemingly uncoordinated urban plan.

The variance in urban design between the two sustainable communities alludes to the nature of the underlying ideological causations. The analysis revealed a sufficient number of syntactic and semantic codes to enable classification of Sippy Downs as a typical postmodern community. However, Masdar City does not fit into the same mould. In contrast to the ambiguous postmodern architecture it exhibits a desire for clear lines, order, beauty, and spirituality, reaching beyond the uncertainty and vagueness of postmodernity.

Transferring these emerging design features of Masdar City on the classification proposed by Sorokin, it appears that Masdar represents the idealistic period of sociocultural change, as according to Sorokin [5, p. 221] the idealistic architecture is "Moderate but marvellously effective in its means, techniques, and instrumentalities. Harmonious in its inner and external synthesis of Ideational and Sensate beauty." In comparison, as demonstrated above, the postmodern/ sensate Sippy Downs university design tends to display a "Most complicated technique, artificially designed to sensually impress, to stun, to "hit"' [5, p. 221]. Since the sensate society is followed by the emergence of idealistic culture according to Sorokin's theory of social change, the selfproclaimed assertion that Masdar is a template for the cities of the future appears to be valid, based on the inference of the previously analysed external indicators of social change.

\section{Implications of the findings of the residents' survey for the processes of social change}

Spengler, Werner, \& Atkinson [41, p. 160] propose that "every culture possesses its own systematic psychology just as it possesses its own style of knowledge of men and experience of life". Similarly, Sorokin postulates that one of the characteristics of a mature culture is that it is integrated into a logicomeaningful system. A logico-meaningful culture displays internally consistent traits which are changing due to the inbuilt nature of the system rather than due to the effect of external forces [5]. Thus Sorokin would take the side of nature in the nature versus nurture debate.

Since the aim of the current study is to gain comprehensive insight into the nature and direction of social change, it is 
pertinent to investigate whether the current postmodern culture in Sippy Downs can be viewed as an integrated logicomeaningful system about to move into the next phase of sociocultural development. Consequently, a survey was devised to ascertain the worldviews of local residents and their visions for the future of their community. These views were compared with established elements of the postmodern worldview, based on architectural signs, and specific indicators of social cohesion $[2,46]$. Additionally, attitudes to sustainability were canvassed to elucidate the possible future direction of the community, considering the next post-postmodern phase of sociocultural development. The consistency of responses across the above parameters points to a high level of logicomeaningful integration of the Sippy Downs community.

The survey of 50 residents of Sippy Downs revealed that they predominantly preferred retro style, colonial, Mediterranean dwellings with unique curved or complex design (36\%) over standard square design (2\%) as demonstrated by Fig. 1. Retro style dwellings pointing to anamnesis, meaning suggested recollection with nostalgia and pastiche [2] are dominant building styles throughout Sippy Downs, thus based on the preferences of respondents the community is already integrated on that particular level.

Further, preferences for types of leisure activities in future developments showed the highest desire for live music $(59.18 \%)$ in a multipurpose community centre (72\%) surrounded by a large variety of dining options (56\%), although there is already a decent selection of restaurants in the area. These responses are consistent with the sensual hedonistic characteristics of the sensate cultural mentality. In comparison, a need for a larger variety of places of worship or religious centres was stipulated by only $10 \%$ of respondents. This result was expected, since spirituality is central to the ideational cultural mentality, but it is sidelined and replaced by science in the current materialistic sensate society [5].

Altogether, $92 \%$ of respondents felt a sense of belonging to their postmodern environment in Sippy Downs, pointing to a high level of social cohesion [47]. Their willingness to welcome immigrants to strengthen the community (favoured by $48 \%$ of respondents), indicates support for multiculturalism. Similar results were found by the national report on social cohesion in Australia reporting that multiculturalism "is established as a strong and supported 'brand', one that resonates with the Australian people" [46, p. 3]. Multiculturalism along with globalisation are considered to be traits of a postmodern era.

Sustainability is an emergent theme worldwide, and already in 2003 in the Maroochy 2025 : community visioning [48] about $69 \%$ of residents of the wider Sunshine Coast area identified protection of the natural environment as very important. In the current survey $50 \%$ of Sippy Downs respondents identified themselves specifically as strong supporters of sustainable development. Accordingly, they chose solar power, water recycling (66\%), parks, nature strip (70\%), public transport $(74 \%)$ and community gardens $(74 \%)$ as desirable features for the future of their local community. Moreover, $50 \%$ of respondents see themselves as individuals rather than a part of their community or a religious group. This result may indicate that individualism and collectivist thinking are reasonably well balanced in the current community. The gradual decline of dominant individualism of late capitalism is a weak signal of imminent transformation in worldviews and aspirations of the inhabitants, leading them towards the idealist era. Working together toward preferred sustainable futures as a hallmark of collectivism would be central to the holistically sustainable city of future fostering an idealistic culture $[49,6]$.

In sum, the community profile of Sippy Downs derived from the survey revealed that the community has characteristics consistent with a logico-meaningfully integrated culture representing a postmodern/sensate society. In addition, a subtle shift was observed towards the next phase of sociocultural development. This phase, determined by Sorokin [5, p. 39] as the idealistic culture mentality is balancing spiritual and materialistic elements with a motto:"live and let live". On the other hand, the socio-semiotic analysis of Masdar City detected a significant number of features consistent with the idealistic culture mentality. The analysis demonstrated how architecture can gently guide society in a new direction [50]. Unlike some other cultures in nearby Asia, Masdar has an advantage of being built in the steadfast Arab cultural environment where traditions and collectivism have not been significantly affected by the hegemonic forces of globalisation and imperial colonialism inherent to late capitalism [51].

\section{Conclusion}

The current study considered aspects of urban design and architecture as external indicators of social change in a context of two master built communities: Masdar City and Sippy Downs. The mixed methods utilised in this study analysed both temporal and spatial perspectives of architecture and urban designs. The temporal perspectives situated the case studies within the framework of Sorokin's theory of social change, enhanced with the analysis of postmodernism as a determining feature of the late sensate phase of societal development. The socio-semiotic analysis informed by the findings of CLA indicated a transition of Masdar City from the late sensate to the idealistic phase of social change, whereas the socio-semiotic analysis paired with the residents' survey indicated that Sippy Downs, in spite of weak signals of idealistic cultural mentality, is still firmly grounded in the late sensate mentality embracing the postmodern worldview. The survey, as part of the mixed design, enhanced the understanding 
of drivers and the underlying processes of social change. However, because of the small sample size the results cannot be considered generalisible. Statistics from the previous comparison study cited were more robust, but since the survey designs differed and questions could only be overlaid to a limited extent, the statistical significance of the results was difficult to ascertain.

The combination of qualitative and quantitative research methods within the framework of mixed methods delivered a multilayered comprehensive picture of the subject of analysis. The opportunity to cross reference and illuminate finer details facilitated by this approach was well worth the extra effort. Therefore mixed methods are recommended for consideration to any futures/foresight practitioner demanding unmatched strength and depth in their research. However, this approach demands a broad knowledge base and high level analytic skills from the intrepid practitioner.

Open Access This article is distributed under the terms of the Creative Commons Attribution License which permits any use, distribution, and reproduction in any medium, provided the original author(s) and the source are credited.

\section{References}

1. Wilber K (2000) A theory of everything: An integral vision for business, politics, science and spirituality. Shambhala, Boulder

2. Jencks C, Keswick M (1987) Post-modernism: The new classicism in art and architecture. Academy Editions, London

3. Wilenius M (2014) Society, consciousness and change - an inquiry into Pentti Malaska's futures thinking. Futures 61:58-67

4. Rorty R (1979) Philosophy and the mirror of nature. Princeton University Press, Princeton

5. Sorokin P (1970) Social \& cultural dynamics, 2nd edn. Porter Sargent Publisher, Boston

6. Daffara P (2004) Macrohistory and city futures. Futur Stud 9(1):1330

7. Harvey D (1992) The condition of postmodernity, an enquiry into the origins of cultural change. Blackwell Publishers, Oxford

8. Sardar Z (1990) Surviving the terminator: the postmodern mental condition. Futures 22(2):203-210

9. Focault M (2003) Society must be defended (trans: Macey D). Picador, New York

10. Inayatullah S (1998) Causal layered analysis: post structuralism as method. Futures 30(8):815-829. doi:10.1016/s0016-3287(98)00086-x

11. Sardar Z (1997) Postmodernism and the other: New imperialism of western culture. Pluto Press, London

12. Allweil Y (2010) Beyond the spatial turn: architectural history at the intersection of the social sciences and built form. In: Spaces of History / Histories of Space: Emerging Approaches to the Study of the Built Environment, College of Environmental Design, University of California Berkeley

13. Brueckner JK, Colwell PF (1983) A spatial model of housing attributes: theory and evidence. Land Econ 59(1):58-69. doi: $10.2307 / 3145876$
14. Rendell J (2014) Space, place, site: Critical spatial practice. Re/ placing public art. University of Minnesota Press, Minneapolis

15. Gottdiener M (1995) Postmodern semiotics - material culture and the forms of postmodern life. Blackwell, Oxford

16. Anthony J (2013) Being a waveform of potential as an experiential choice - emergent dynamic qualities of identity and integrity. http://www.laetusinpraesens.org/musings/waves.php\#attr. Accessed September 17, 2013

17. Galtung J, Inayatullah S (1997) Macrohistory and macrohistorians: Perspectives on individual, social, and civilizational change. Praeger, Westport

18. Rorty R (1991) Objectivity, relativism, and truth, vol 1, Philosophical papers. Cambridge University Press, Cambridge

19. Minda G (1995) Postmodern legal movements: Law and jurisprudence at century's end. NYU Press, New York

20. Bussey M (2014) Concepts and effects: ordering and practice in foresight. Foresight 16(1):1-16

21. Fielding N (2008) Analytic density, postmodernism, and applied multiple method research. In: Bergman MM (ed) Advances in mixed methods research. Sage Publications, London

22. Bergman MM (2008) Advances in mixed methods research. Sage Publications, London

23. Creswell JW, Plano Clark VL (2006) Designing and conducting mixed method research. Sage Publications, London

24. Karlsen JE, Overland EF, Karlsen H (2010) Sociological contributions to futures' theory building. Foresight 12(3):59-72

25. Inayatullah S (2007) Questioning the future, methods and tools for organisational and societal transformation, 3rd edn. Tamkang University, Taipei

26. Bussey M (2014) CLA as process: mapping the theory and practice of the multiple. J Futur Stud 18 (4)

27. Daffara P (2010) Sorokin, Pitirim. The Oxford International Encyclopedia of Peace

28. Sardar BZ (2013) Future: All that matters. Hodder \& Stoughton, London

29. Al Jaber A (2013) Ceo message. Masdar Times 1(8):2

30. Sippy Downs - Palmview (2014) Sunshine Coast Council. http:// profile.id.com.au/sunshine-coast/about/?WebID=480. Accessed September 10, 2013

31. Joss S (2010) Eco-cities - a global survey 2009. WIT Trans Ecol Environ 129:239-250

32. Kraidy MM (1999) The global, the local, and the hybrid: a native ethnography of glocalization. Crit Stud Mass Commun 16(4): 456-476

33. Dabashi H (2012) The arab spring: The end of postcolonialism. Zed Books

34. Lau A (2012) Masdar City: A model of urban environmental sustainability. http://www.stanford.edu/group/journal/cgi-bin/wordpress/ wp-content/uploads/2012/09/Lau_SocSci_2012.pdf. Accessed February 20, 2013

35. Mueller P (2013) Masdar: City of the future. http://mastmedia.plu. edu/2013/10/28/masdar-city-of-the-future/. Accessed December 5, 2014

36. Biggs J (2013) Changing universities. Strictly Literary, Ballan

37. Inayatullah S (2008) Mapping educational futures: Six foundational concepts and the six pillars approach. In: Bussey M, Inayatullah S, Milojevic I (eds) Alternative educational futures: Pedagogies for emergent worlds, vol 21. Sense Publishers, Rotterdam, pp 13-39

38. Galtung J (1996) Peace and conflict research in the age of the cholera: ten pointers to the future of peace studies. Int J Peace Stud 1 (1)

39. Milojevic I (1996) History, feminism and futures. Futures 29(6/7): 629-632

40. Clayton AMH, Radcliffe NJ (1996) Sustainability : a systems approach. Earthscan, London

41. Spengler O, Werner H, Atkinson CF (1991) The decline of the West (trans: Atkinson CF). abridged, reprint edn. Oxford University Press, 
42. JMA, Architects (2003) Profile. http://www.jma-arch.com/profile.html. Accessed August 20, 2014

43. Sutton D (2007) Islamic design a genius for geometry. Walker Publishing, NY

44. Eco U (1969) Function and sign: The semiotics of architecture. In: Gottdiener M, Lapopoulos AP (eds) The City and the sign: an introduction to urban semiotics. Columbia University, New York, pp 182-202

45. Hillenbrand R (1999) Islamic art and architecture. Thames and Hudson Ltd., London

46. Markus A (2013) Mapping social cohesion. Monash University, Caulfield East, Australia
47. Forsyth D (2005) Group dynamics. Cengage Learning, Melbourne

48. MaroochyCouncil (2005) Maroochy 2025: community visioning. The Council, Nambour

49. Daffara P (2004) Sustainable city futures. In: Inayatullah S (ed) The casual layered analysis (CLA) reader. Tamkang University Press, Taipei, pp 424-438

50. Nesbitt K (1996) Theorising a new agenda for architecture. Princeton Architectural Press, New York

51. Lenin VI (1963) Imperialism, the highest stage of capitalism. In: Lenin selected works, vol 1. Progress Publishers, Moscow, pp 667766 